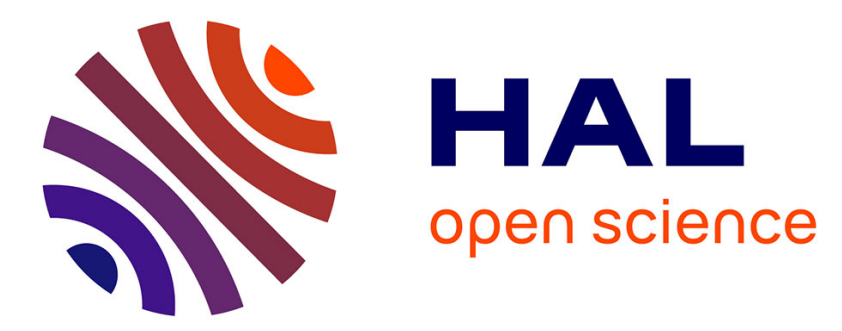

\title{
A cruciform shape to study the influence of strain paths on forming limit curves
}

Lionel Leotoing, Dominique Guines, Shunying Zhang, Eric Ragneau

\section{To cite this version:}

Lionel Leotoing, Dominique Guines, Shunying Zhang, Eric Ragneau. A cruciform shape to study the influence of strain paths on forming limit curves. 16th annual ESAFORM Conference on Material Forming, Apr 2013, Aveiro, Portugal. pp.41-46, 10.4028/www.scientific.net/KEM.554-557.41 . hal00872576

\section{HAL Id: hal-00872576 https://hal.science/hal-00872576}

Submitted on 27 Mar 2014

HAL is a multi-disciplinary open access archive for the deposit and dissemination of scientific research documents, whether they are published or not. The documents may come from teaching and research institutions in France or abroad, or from public or private research centers.
L'archive ouverte pluridisciplinaire HAL, est destinée au dépôt et à la diffusion de documents scientifiques de niveau recherche, publiés ou non, émanant des établissements d'enseignement et de recherche français ou étrangers, des laboratoires publics ou privés. 


\title{
A cruciform shape to study the influence of strain paths on forming limit curves
}

\section{Lionel LEOTOING ${ }^{a}$, Dominique GUINES ${ }^{b}$, Shunying $Z \mathrm{HANG}^{\mathrm{c}}$ and Eric RAGNEAU ${ }^{d}$}

\author{
Université Européenne de Bretagne (UEB), INSA-LGCGM-EA3913 \\ 20 av. des Buttes de Coësmes, CS 70839, 35708 Rennes Cedex 7, France \\ alionel.leotoing@insa-rennes.fr, bdominique.guines@insa-rennes.fr, 'shunying.zhang@insa- \\ rennes.fr, ${ }^{d}$ eric.ragneau@insa-rennes.fr
}

Keywords: Forming Limit Curves (FLC), cruciform shape, strain paths, AA5086.

\begin{abstract}
.
The optimization of sheet metal forming processes requires an accurate prediction of material behavior and forming abilities, especially for aluminum alloys which exhibit generally a low formability compared with typical mild steels. This study presents an original technique based on the use of a cruciform shape for experimental characterization and numerical prediction of forming limit curves (FLCs). By using a cruciform shape, the whole forming limit diagram is covered with a unique geometry thanks to the control of the displacements in the two main directions of the specimen. The test is frictionless and the influence of linear and non-linear strain paths can be easily studied since the strain path is controlled by the imposed displacements, independently on the specimen geometry. The influence of strain paths is first studied by introducing a linear prestrain (uniaxial, plane strain or equi-biaxial), in rolling direction. Afterwards non-linear prestrain paths are also tested.
\end{abstract}

\section{Introduction}

In sheet metal forming operations, the sheet can be deformed only up to a certain limit, defined as its formability. Many factors, like temperature, strain rate or strain paths can affect considerably the material formability. The optimization of forming operations with numerical tools needs accurate predictions of material formability in order to fully exploit its forming abilities. Thus, understanding and characterizing the formability of metal sheets are essential for controlling final product quality and then evaluating the success of the sheet forming operations.

The most popular tool to quantify the formability of sheet metals is the forming limit diagram (FLD). A FLD is a strain diagram built with the in-plane principal strains in which the forming limit curve (FLC) can distinguish between safe points and necked points. The determination of FLDs has always been the subject of extensive experimental, analytical or numerical studies. Experimentally, two conventional tests exist, the so-called out-of-plane stretching (e.g. Nakajima test) and the inplane stretching (e.g. Marciniak test). The main drawbacks of these tests are the use of a high number of specimens with various geometrical specifications, the influence of friction and the description of formability by following simplistic linear strain paths. Many predictive tools have been established for FLCs. The Marciniak and Kuczynski model (known as the M-K model) is a widely used analytical tool but its initial geometrical imperfection factor is uncertain. The value can be adjusted by making the best fit with experimental results or by making a microstructural analysis of the metallic sheet. Moreover, the choice of an appropriate constitutive law is a key to obtaining the practical prediction of FLCs.

The use of a cruciform shape to characterize and predict forming limit curves can be an interesting alternative to overcome the major drawbacks of the conventional methods. The test is 
frictionless and the main advantage of this shape is that the strain path at the onset of necking is directly imposed by the control of the testing machine, independently on the specimen geometry. A unique geometry is then sufficient to cover the whole forming limit diagram, the influence of strain path can be easily studied by applying linear or non-linear loadings. Numerically, the use of the finite element method to model the cruciform shape permits the implementation of complex mechanical behaviors in order to evaluate the influence of operating conditions like temperature or strain rate. Moreover, the calibrating step of the initial geometrical imperfection factor which is essential for M-K models is unnecessary.

The present study focuses on the potential of the cruciform shape to study the effect of strain path on the formability. Many authors [1], have demonstrated that non-linear loadings, frequently encountered in industrial processes, have a great influence on level and shape of FLCs. In literature, most of the studies employs the M-K model [2,3] with the limits previously mentioned. Experimentally, it is rather difficult to apply a prestrain with the conventional tests and very few experimental data exist [4].

In this work, the finite element model of the cruciform shape is first presented and its ability to evaluate the influence of strain path on the formability of the aluminum alloy 5086 is clearly demonstrated. Linear or non-linear prestrains effects can be observed for different modeling of the hardening law.

\section{The cruciform shape}

In order to control the strain path of the necking zone thanks to the displacements of the four arms of the cruciform shape, the onset of necking must be observed in the central zone. A promising specimen shape (Fig. 1) following this requirement has been previously optimized by present authors [5,6]. The onset of necking is detected when the equivalent plastic strain increment ratio between two zones (necking and adjacent zone) reaches a critical value [5].

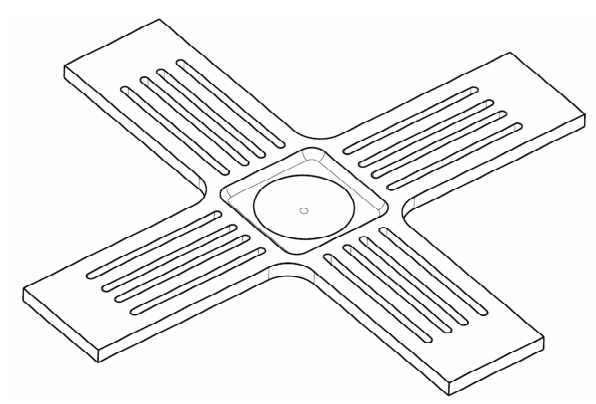

Fig. 1: Optimized cruciform shape

Due to the symmetrical properties of the specimen, only one-quarter is considered in the finite element model (Fig. 2). For meshing, tetrahedral elements are applied and a refined mesh is adopted where strain localization may appear (central zone, fillet, grooves).

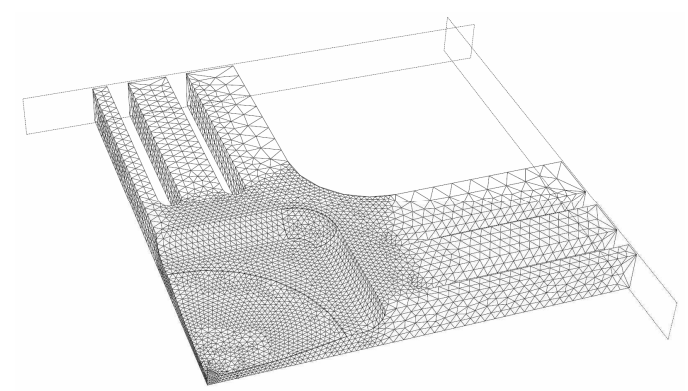

Fig. 2: One-quarter meshed of the cruciform shape 
Firstly, the classical power law of Ludwick (Eq. 1) is used to model the hardening behavior of the material.

$$
\bar{\sigma}=\overline{\sigma_{0}}+\mathrm{K} \bar{\varepsilon}^{-\mathrm{n}}
$$

In equation (1), $\bar{\sigma}$ and $\bar{\varepsilon}$ are respectively the equivalent stress and the equivalent plastic strain. The three constants are given by: $\overline{\sigma_{0}}=125.9 \mathrm{MPa}, \mathrm{K}=447.1 \mathrm{MPa}$ and $\mathrm{n}=0.41$. The hardening curve associated with the Ludwick's power law is given by Fig. 3.

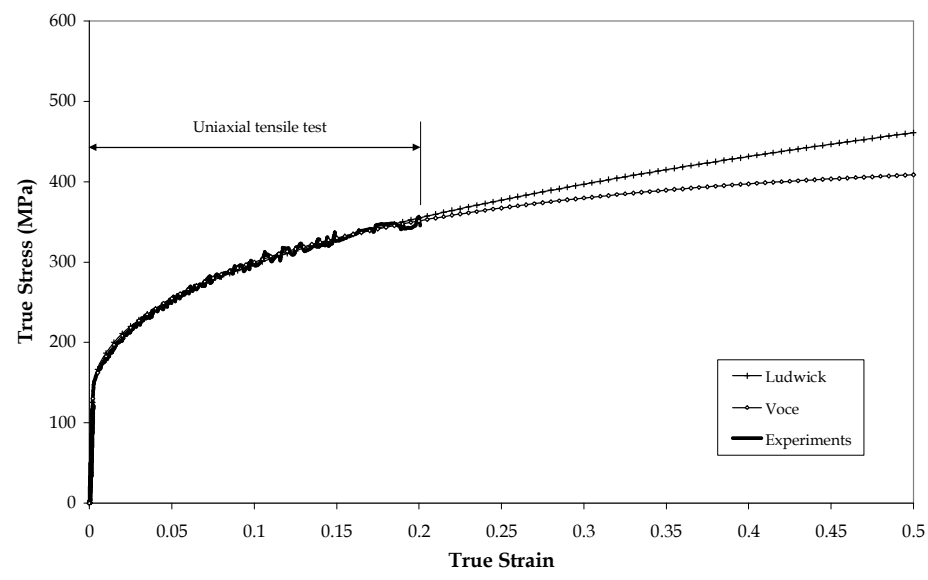

Fig. 3: Hardening curves for Ludwick's and Voce's law

The anisotropy of the material is described with the Hill48 yield criterion in which the equivalent stress is expressed by a quadratic function (Eq. 2):

$$
2 \bar{\sigma}^{2}=\mathrm{F}\left(\sigma_{\mathrm{y}}-\sigma_{\mathrm{z}}\right)^{2}+\mathrm{G}\left(\sigma_{\mathrm{z}}-\sigma_{\mathrm{x}}\right)^{2}+\mathrm{H}\left(\sigma_{\mathrm{x}}-\sigma_{\mathrm{y}}\right)^{2}+2 \mathrm{~L}{\sigma_{\mathrm{yz}}}^{2}+2 \mathrm{M} \sigma_{\mathrm{zx}}{ }^{2}+2 \mathrm{~N} \sigma_{\mathrm{xy}}{ }^{2}
$$

with $\mathrm{F}=0.7, \mathrm{G}=0.637, \mathrm{H}=0.363, \mathrm{~L}=1.5, \mathrm{M}=1.5$, and $\mathrm{N}=1.494$, constants specific to the state of anisotropy of the material. The direction $\mathrm{x}$ is the rolling direction, $\mathrm{y}$ the transverse direction and $\mathrm{z}$ the normal direction.

\section{Effect of linear prestrains}

The material is prestrained to two different strains levels in the rolling direction (RD) under uniaxial (TU), plane (PS) and equibiaxial (BS) strain state. All the prestrain paths are linear.

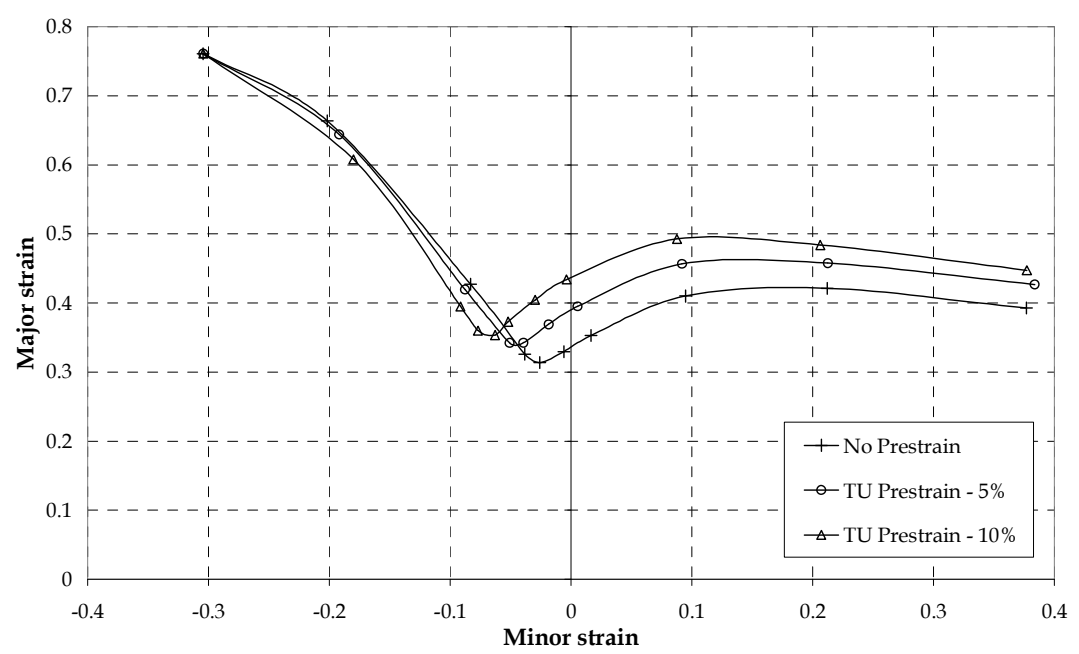

Fig. 4: Effects of uniaxial prestrain in RD 
Fig. 4 shows the effects of two uniaxial prestrain levels (5\% and $10 \%)$ on the prediction of forming limit curves. In this case, the formability globally increases with the level of prestrain and the minimum of the FLC moves to the left hand side of the forming limit diagram.

For a prestrain of $5 \%$ and $10 \%$ in the plane strain state (Fig. 5), the effect is moderate. An increase of the formability is mainly observed for equibiaxial strain paths in the right hand side of the diagram. On the other hand, Fig. 6 shows that a low equibiaxial prestrain $(2 \%$ or $5 \%)$ can lead to a significant reduction of the formability, especially in the critical zone of the plane strain state in which the major strain presents a minimum.

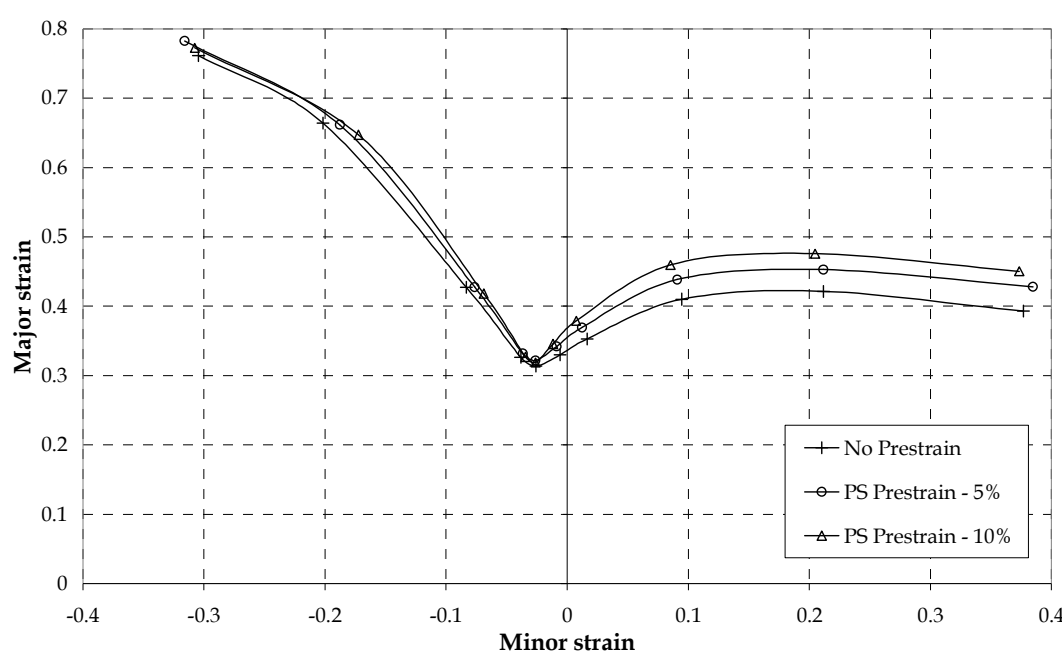

Fig. 5: Effects of prestrain in plane strain state in RD

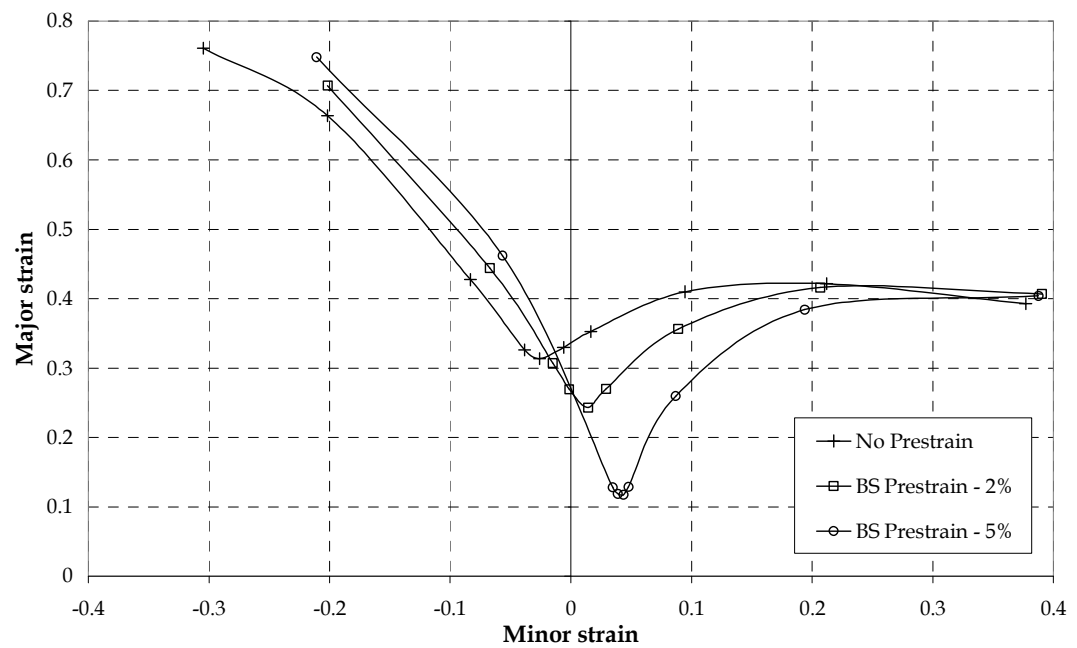

Fig. 6: Effects of equibiaxial prestrain

The model of the cruciform shape clearly shows the effects of a linear prestrain on the formability of the sheet. Moreover, the tendencies observed for the three prestrain states are in complete agreement with the experimental results of Graf and Hosford [4] for an aluminum alloy $6111 \mathrm{~T} 4$.

\section{Effect of material behavior modeling}

The above results are given with a Ludwick's hardening law. The choice of the hardening law for the finite element modeling of the cruciform shape can have a noticeable influence on the 
formability prediction. To illustrate this purpose, a Voce's law (Eq. 3 with $\overline{\sigma_{0}}=130.2 \mathrm{MPa}$, $\mathrm{Q}=300.4 \mathrm{MPa}$ and $\mathrm{B}=3.94$ ) is implemented (hardening curve in Fig. 3) and a comparison with the previous results is made for the specific case of the uniaxial prestrain in the rolling direction.

$$
\bar{\sigma}=\overline{\sigma_{0}}+\mathrm{Q} \sqrt{1-\mathrm{e}^{-\mathrm{B} \bar{\varepsilon}}}
$$

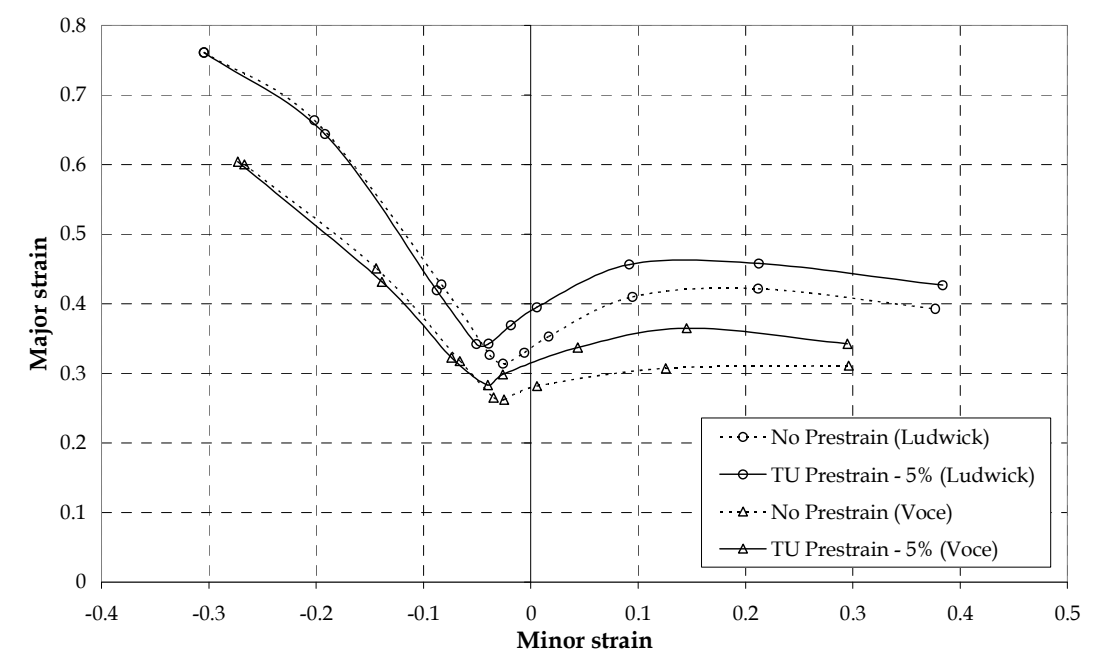

Fig. 7: Effect of hardening law on formability under uniaxial prestrain in RD

The Fig. 7 confirms the influence of the hardening law on formability predictions without prestrain. For the two laws, uniaxial prestrain enhances the formability and this improvement is of the same order.

\section{Effect of non-linear prestrain}

All the results in literature concerning the influence of strain path on formability have been proposed using linear prestrains. As seen before, the cruciform shape permits to model a linear prestrain but it presents a considerable advantage since the application of non linear prestrains is also possible. The effect of a non linear prestrain is shown for an equibiaxial prestrain state in which the final prestrain of 5\% is reached by three different ways: C1 (linear), C2 and C3 (Fig. 8).

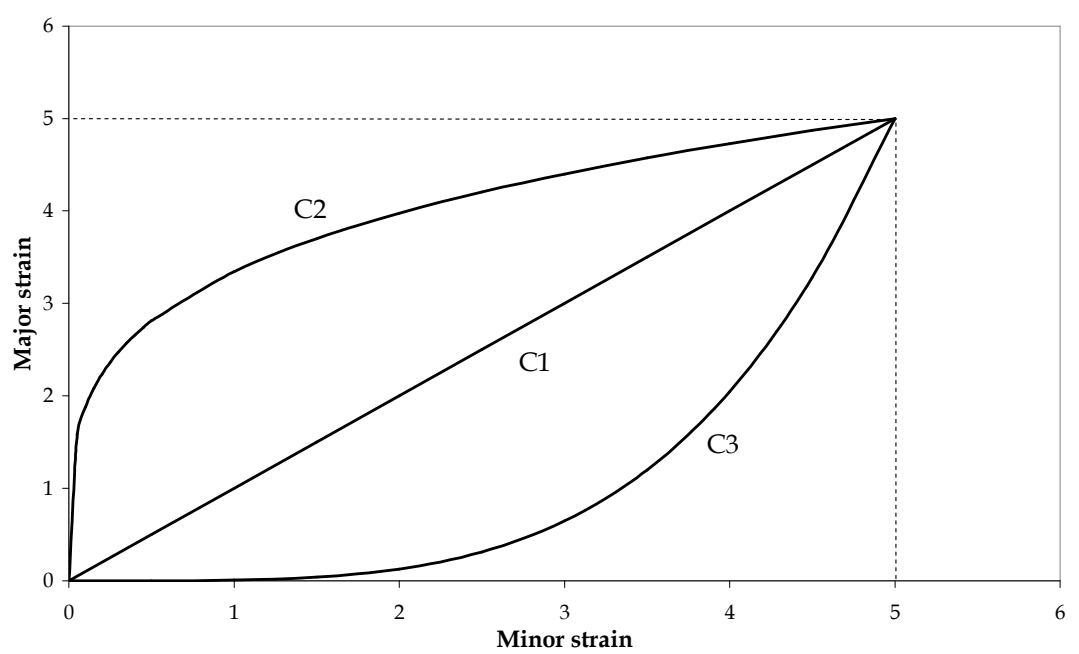

Fig. 8: Different prestrain paths for an equibiaxial prestrain of 5\% 
For the three paths (C1, C2 and C3), the impact on the shape of the FLC is shown in Fig. 9. A difference exists between the three predictions and the type of non linearity affects the critical zone where the value of the major strain is minimum. This tendency is dependent on the choice of the yield criterion since the beginning of $\mathrm{C} 2$ and $\mathrm{C} 3$ is mainly oriented respectively in the rolling direction and in the transverse direction.

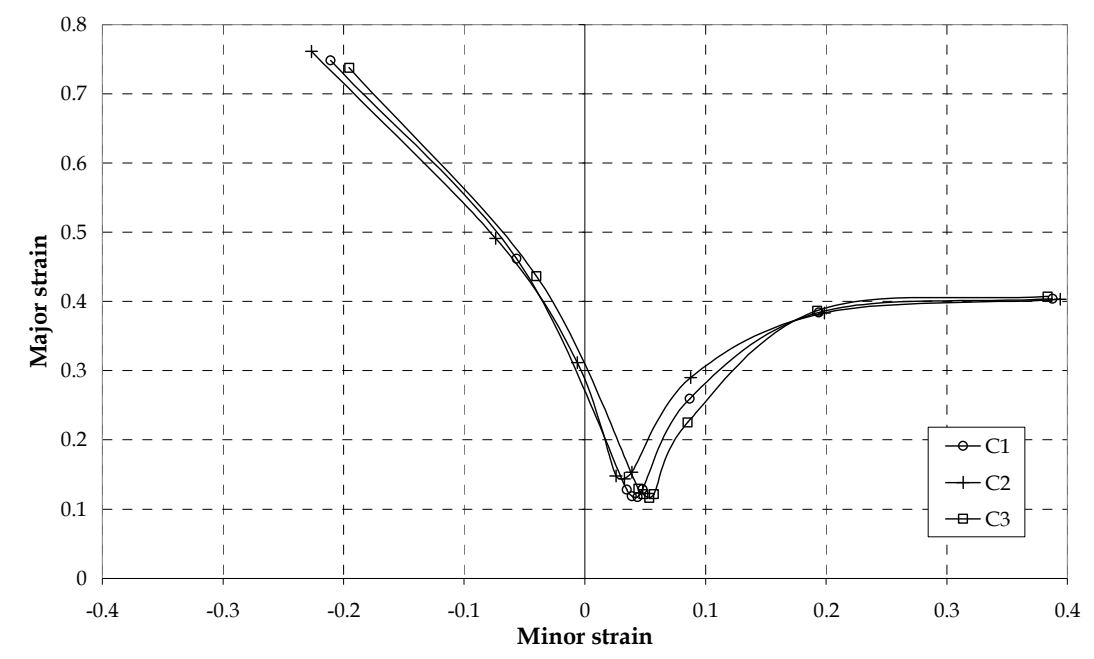

Fig. 9 : Effect of non-linear prestrain

\section{Conclusions}

The ability of the cruciform shape to predict the effect of non linear paths is then clearly demonstrated. Classical tendencies in literature with linear prestrains are observed and if the modeling of the hardening law affects the level and shape of the forming limit curve, the evolution of formability with prestrain is comparable for the two tested laws. The main advantage of this tool is that non linear prestrains can be easily applied and for the studied case an evolution of the formability in the critical zone of plane strain is observed.

\section{References}

[1] A. Barata Da Rocha, F. Barlat, J. Jalinier, Prediction of the forming limit diagrams of anisotropic sheets in linear and non-linear loading, Materials Science and Engineering, 68 (1984) 151-164.

[2] J. Cao, H. Yao, A. Karafillis, M.C. Boyce, Prediction of localized thinning in sheet metal using a general anisotropic yield criterion, International Journal of Plasticity, 16 (2000) 1105-1129.

[3] A. Assempour, R. Hashemi, K. Abrinia, M. Ganjiani, E. Masouni, A methodology for prediction of forming limit stress diagrams considering the strain path effect, Computational Materials Science, 45 (2009) 195-204.

[4] A. Graf, W. Hosford, The influence of strain-path changes on forming limit diagrams of Al 6111 T4, Int. J. Mech. Sci., 36 (1994) 897-910.

[5] I. Zidane, D. Guines, L. Leotoing, E. Ragneau, Development of an in-plane biaxial test for forming limit curve (FLC) characterization of metallic sheets, Measurement Science and Technology, 21 (2010) 1-11.

[6] L. Leotoing, D. Guines, I. Zidane, E. Ragneau, Cruciform shape benefits for experimental and numerical evaluation of sheet metal formability, Journal of Materials Processing Technology (2013), http://dx.doi.org/10.1016/j.jmatprotec.2012.12.013 